\title{
BMJ Open Health and well-being in small island communities: a cross-sectional study in the Solomon Islands
}

\author{
Takuro Furusawa (10 , ${ }^{1,2,3}$ Freda Pitakaka, ${ }^{4}$ Spencer Gabriel, ${ }^{4}$ Akira Sai, ${ }^{5}$ \\ Takahiro Tsukahara, ${ }^{2,6,7}$ Takafumi Ishida ${ }^{1,2}$
}

To cite: Furusawa $T$, Pitakaka F, Gabriel S, et al. Health and well-being in small island communities: a cross-sectional study in the Solomon Islands. BMJ Open 2021;11:e055106. doi:10.1136/ bmjopen-2021-055106

- Prepublication history and additional supplemental material for this paper are available online. To view these files, please visit the journal online (http://dx.doi.org/10.1136/ bmjopen-2021-055106)

Received 02 July 2021 Accepted 25 October 202

\section{Check for updates}

(C) Author(s) (or their employer(s)) 2021. Re-use permitted under CC BY-NC. No commercial re-use. See rights and permissions. Published by BMJ.

${ }^{1}$ Graduate School of Asian and African Area Studies, Kyoto University, Kyoto, Japan ${ }^{2}$ Graduate School of Science, The University of Tokyo, Tokyo, Japan

${ }^{3}$ Interdisciplinary Unit for Global Health, Kyoto University, Kyoto, Japan

${ }^{4}$ Solomon Islands Ministry of Health and Medical Services, Honiara, Solomon Islands

${ }^{5}$ Faculty of Health Sciences, Hokkaido University, Sapporo, Japan

${ }^{6}$ Faculty of Health and Welfare Science, Nayoro City University, Nayoro, Japan

${ }^{7}$ Faculty of Medicine, Tokyo Women's Medical University, Tokyo, Japan

Correspondence to Professor Takuro Furusawa; takuro.f@gmail.com

\section{ABSTRACT}

Objectives This study explored the health problems of inhabitants of small South Pacific Islands under the influence of climate change, focusing on three communities in the Solomon Islands.

Design Cross-sectional study of the Solomon Islands' populations.

Setting A field survey was conducted in Taro Island, a small, urbanised island with a whole-community relocation plan; Manuopo community of Reef Islands, a small remote island on an atoll environment and Sasamungga, an intermediately urbanised community on a larger island. The Sasamungga community was used for comparison. Participants Each community's participants were recruited through local health authorities, and 113,155 and 116 adults (aged 18+ years) from Taro, Manuopo and Sasamungga, respectively, participated voluntarily.

Methods Each participant's body height, weight and body mass index were measured. A drop of blood was sampled for malaria testing; glycated haemoglobin and $C$ reactive protein levels, measured from another drop of blood, were markers for diabetes and inflammation, respectively. The Primary Care Screening Questionnaire for Depression measured depressive mental states.

Primary and secondary outcome measures Regarding health status, the dependent variables-communicable diseases, non-communicable diseases and mental state - and independent variables-differences in communities and socioeconomic status - were measured through health checkups and interviews of individual participants.

Results Taro Island inhabitants had a higher risk of obesity (OR 1.13, 95\% $\mathrm{Cl} 1.02$ to $1.27, \mathrm{p}=0.0189$ ), and Manuopo inhabitants had a higher risk of depression $(1.25,95 \% \mathrm{Cl} 1.08$ to $1.44, p=0.0026$ ) than Sasamungga inhabitants. Manuopo inhabitants recognised more serious problems of food security, livelihood, place to live and other aspects of daily living than other communities' inhabitants.

Conclusions The three small island communities' observation identified different health problems: the urbanised community and remote community had a high risk of non-communicable diseases and mental disorders, respectively. These health problems should be monitored continuously during future climate-related changes.

\section{INTRODUCTION}

Human-induced climate change is now a real threat to human health and well-being. ${ }^{1-3}$

\section{STRENGTHS AND LIMITATIONS OF THIS STUDY}

$\Rightarrow$ This study directly measured human health and well-being among the inhabitants of the Pacific Islands.

$\Rightarrow$ The incidence of communicable and noncommunicable diseases, including mental health, was assessed as the current baseline health status to monitor future changes.

$\Rightarrow$ The study was conducted in three types of communities: an atoll, an overcrowded, and a comparison community on volcanic islands, for which epidemiological data are rarely available.

$\Rightarrow$ The number of participants ( $\mathrm{N}=384$ ) was limited and not all potential confounding factors were controlled in the analyses.

$\Rightarrow$ Because of lack of comparable data, further studies are necessary to monitor prevalence of the depressive conditions.

WHO indicated that climate change affects environmental systems that determine health and the socioeconomic and cultural modifiers of risks to health, thereby impacting health as well. ${ }^{4}$ Woodward $e t$ al suggested that there has been a major increase in health problems because of intense heat waves and fires; undernutrition resulting from diminished food production in poor regions; lost work capacity and reduced labour productivity in vulnerable populations; and foodborne, waterborne and vectorborne diseases. ${ }^{5}$ In addition, Fritze et al suggested that extreme weather events increased post-traumatic stress disorders, and the resulting environmental damage caused loss of work and had other consequences. ${ }^{6}$ The 'loss of connection to a place and sense of belonging associated with displacement' (eg, involuntary migration) also led to psychological stress. ${ }^{6}$

Lifestyle changes can be a risk factor for infectious diseases, and changes from a traditional subsistence to a cash economy increase the incidence of non-communicable diseases (NCDs), such as obesity, diabetes 
and hypertension. In the South Pacific Islands, infectious diseases and malnutrition are still severe problems. At the same time, diabetic, metabolic and cardiovascular diseases are now highly prevalent. People, therefore, face the double burden of increased risk of communicable diseases and NCDs. ${ }^{7}$ In reality, the NCD Risk Factor Collaboration showed that the risks of infectious diseases and malnutrition are high in Pacific Island countries with low-income economies, ${ }^{8}$ and NCDs increase during disaster events such as when the inhabitants were evacuated to temporary camps near townships during the 2007 Solomon Islands earthquake and tsunami. ${ }^{9}$

Therefore, the WHO Division of Pacific Technical Support with its partner countries suggested that the small island countries of the Pacific are vulnerable to climate change. In these Pacific Islands, the high-priority, climate-sensitive health risks are suggested to be trauma from extreme weather events, heat-related illnesses, safety and security of waterborne and foodborne, vectorborne diseases, zoonoses, respiratory illnesses, psychosocial ill health, NCDs, population pressures and health system deficiencies. ${ }^{10}$

Taro Island of the Solomon Islands is known to be one of the communities most vulnerable to a rise in sea level ${ }^{11} 12$ because it is much smaller than the other independent states in the South Pacific (eg, Tuvalu). However, the actual health status of small island communities, especially in remote islands, has rarely been studied. It is, thus, necessary to reveal and record the real health status of the small island communities that have recently been affected by and are likely to be further influenced by climate change. As Haines et alsuggested, monitoring and surveillance are needed for this purpose to (1) identify important changes in disease incidence, health risk indicators, and health status; (2) determine whether these changes are likely to be the result of local, regional or global environmental changes; (3) help develop countermeasures and assess their effectiveness and (4) develop hypotheses about the potential health effects of climate change. $^{2}$

Accordingly, this study aimed to explore health problems in small South Pacific Island communities that are affected by climate change through health check-ups and interview surveys in three communities in the Solomon Islands. The research assessed communicable diseases and NCDs, including mental disorders. Special attention was paid to health risks in the two communities that were most vulnerable to sea-level rise compared with a community on a large island. This study also aimed to provide a baseline of health information for these communities, which could be referenced should relocation or other adaptation strategies materialise.

\section{METHODS}

\section{Study sites}

The Solomon Islands (population=approximately 650 000) constitute more than 900 islands. More than $80 \%$
Table 1 Basic characteristics of the selected villages

\begin{tabular}{llll}
\hline & Sasamungga & Taro & Manuopo \\
\hline Province & Choiseul & Choiseul & Temotu \\
\hline $\begin{array}{l}\text { Effects of sea- } \\
\text { level rise }\end{array}$ & Minimum & Severe & Severe \\
\hline $\begin{array}{l}\text { Health facility } \\
\text { Hospital } \\
\text { (no doctor } \\
\text { stationed) }\end{array}$ & Hospital & Clinic \\
\hline $\begin{array}{l}\text { Estimated } \\
\text { population* }\end{array}$ & 1000 & 810 & 1030 \\
\hline $\begin{array}{l}\text { Participating } \\
\text { households, } \mathrm{n}\end{array}$ & 92 & 89 & 131 \\
\hline $\begin{array}{l}\text { Participants } \\
\text { (adults), } \mathrm{n}\end{array}$ & & & \\
\hline \multicolumn{1}{|l}{ Male } & 37 & 43 & 39 \\
\hline $\begin{array}{l}\text { Female } \\
\text { Total }\end{array}$ & 116 & 73 & 116 \\
\hline $\begin{array}{l}\text { Participants' } \\
\text { age in years, } \\
\text { mean (min- } \\
\text { max) }\end{array}$ & 49 (20-79) & 42 (18-85) & 46 (18-79) \\
\hline
\end{tabular}

*Estimated population size, as cited in government reports. ${ }^{13} 16$

of the population of these islands lives in places remote from urban infrastructure and follows a subsistence way of life that relies on traditional agriculture and fishing. ${ }^{13}$ This study was conducted in three villages chosen for their representativeness of the main types of communities found on the islands: they are all central communities in their respective regions and have hospitals or clinics (table 1, figure 1).

Taro is the name of both the community and the island. Taro is the provincial capital of Choiseul Province and has about 810 inhabitants. Taro Island has a land area of only $0.44 \mathrm{~km}^{214}$ and is vulnerable to rising sea levels. Therefore, the Choiseul Government has developed a relocation plan to permanently move all Taro Island inhabitants and infrastructure to the main island of

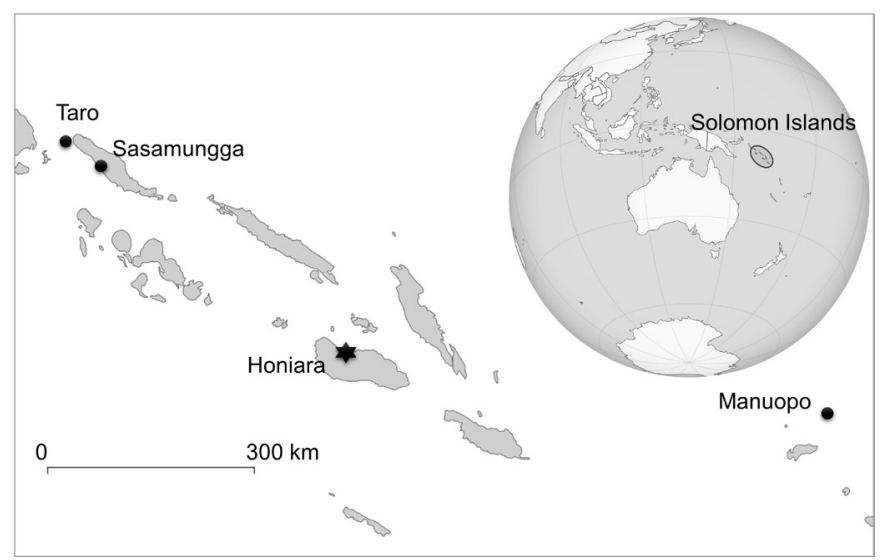

Figure 1 Map showing the communities selected in this research. 
Choiseul, approximately $2 \mathrm{~km}$ from Taro. ${ }^{6}$ This is the first plan for a community-level relocation in the country, even though many other small islands are also at risk of a rise in sea level. ${ }^{15}$ Since there is almost no suitable agricultural land on the island, people purchase food from vendors who travel from Choiseul Island by canoe every day.

Manuopo is a village on Lomlom Island of the Reef Islands in Temotu Province. The Reef Islands are atoll islands that are free from the type of urban infrastructure found on large islands. The Manuopo village community is also at risk of being affected by the rising sea level. Unlike Taro, the people of Manuopo are rarely able to obtain food or other kinds of goods from the main island and need to produce sufficient food, building materials, drinking water and other products on the atoll. Although no official evaluation of the impact of sea-level rise is available for the Reef Islands, soil erosion, land inundation and loss of coastal vegetation have been observed here. ${ }^{16}$ Manuopo has the largest population among the Reef Islands, with 1030 inhabitants, and it has a clinic that serves as the local healthcare centre for the islands. ${ }^{17}$

Sasamungga is one of the biggest villages (of about 1000 inhabitants) on the main island of Choiseul. ${ }^{14}$ It was chosen as a comparison community because the rising sea level has almost no influence on this village since it is located on a large volcanic island and neither the village nor the coastal vegetation are directly affected by the sealevel rise.

Therefore, these three villages are suitable for crosssectional research to explore the effect of the rise in sea level and provide baseline data for future changes.

\section{Participants}

Health check-up and interview surveys were conducted in December 2017 and July 2018 in Choiseul Province (Taro and Sasamungga) and Temotu Province (Manuopo), respectively. Participants were recruited from all community members without any selection as follows.

The research team prepared posters that explained the project and invited inhabitants to participate in the survey in advance and sent them to local hospital directors, health authorities and community leaders. The directors, health staff and leaders displayed the posters on public bulletin boards as well as introduced them during community meetings. In the Solomon Islands, bulletin boards and community meetings are a means of communicating public information to all people without partiality or discrimination. It was also specified that a tin of fish (equivalent to about US\$2) would be given as a reward to every participant. In this process, participants were invited to voluntarily visit hospitals or clinics for health check-ups during the survey period. At the reception for the check-ups, the research team explained the study's purpose and method as well as the protection of privacy/personal information. They also explained how data would be used and accessed, and that potential participants would not be penalised if they chose not to participate. Other relevant items were also discussed.
If a person or legal guardian agreed to participate, they signed informed consent forms.

This project accepted all individuals for health check-ups; however, blood pressure measurement, questionnaire survey on mental condition, and interviews on household economic status were conducted exclusively for adults. As a result, 146, 138 and 228 inhabitants from Sasamungga, Taro and Manuopo, respectively, participated in the research. Although no exact census data are available for the study period, the latest population information suggested that these islands had a population of 1000,810 , and 1030, and thus, this study's participants covered $14.6 \%, 17.0 \%$, and $22.1 \%$ of the inhabitants, respectively. Further, this study included only adults (aged 18 years or above). Thus, from among the initial participants, 33, 22 and 73 children aged 17 years or below were excluded from this study for each island, respectively. In total, 113 adults from 92 households, 116 adults from 89 households, and 155 adults from 131 households were included from Sasamungga, Taro, and Manuopo, respectively (table 1 ).

We aimed to gather a sample of more than $10 \%$ of the populations of the communities. It was difficult to recruit a large number of participants, given the field conditions of the Solomon Islands and our policy of voluntary participation. On the other hand, we had estimated that a sample size of 350 was sufficient to achieve statistical power (one minus beta), with $90 \%$ under the condition to detect an odds ratio (OR) of 1.5 in the multiple logistic regression analysis with statistical significance (alpha) $<5 \%$ as a priori sample size estimation, using the G*Power software (Heinrich-Heine-Universität Düsseldorf). Moreover, as statistical power calculation tends to be low for logistic regression analyses, our sample size was adequately large (99\% statistical power) to perform multiple regression analyses with six variables.

\section{Patient and public involvement}

Before conducting this study, we had discussions with officials in Choiseul and Temotu Provinces and incorporated the issues raised into the research plan. We also held discussions with local community leaders and inhabitants. As a result, the premiers of Choiseul and Temotu submitted letters of support for the study and approved the plan for permission from the Solomon Islands National Ethics Committee.

\section{Health check-up}

During the health check-up, each participant's body height was measured to the nearest $1 \mathrm{~mm}$ using a field anthropometer (Tsutsumi, Japan), and their weight was recorded to the nearest $0.1 \mathrm{~kg}$ using a portable digital scale (Tanita model HD-654, Tanita, Japan), according to a standard protocol. Body mass index (BMI; $\mathrm{kg} / \mathrm{m}^{2}$ ) was then calculated. Blood pressure was measured twice using an Omron HBP-1300 device (Omron Corporation, Japan), and the average was used for analyses. 
A drop of blood was sampled using the finger-prick method. Glycated haemoglobin (HbAlc) was measured as a marker for diabetes (Afinion NycoCard system, Abbott, USA). C reactive protein (CRP) was also measured as an inflammation marker in the NycoCard system. Another drop of blood was used for the malaria rapid diagnosis test (Entebbe Malaria Rapid Test, Laboratorium Hepatika, Indonesia).

The Primary Care Screening Questionnaire for Depression (PSQ4D) was used to measure depressive mental states. ${ }^{18}$ This questionnaire consists of the following four questions, and answering 'yes' to three or more questions is recognised as depression: (1) 'Have you been experiencing sadness or depressed mood during the last 2 weeks or longer?', (2) 'Have you been experiencing loss of interest or loss of pleasure in doing things during the last 2 weeks or longer?', (3) 'Have you been feeling excessively tired or without energy during the last 2 weeks or longer?' and (4) 'Have you been suffering from sleeplessness during the last 2 weeks or longer?'. All four questions are related to four symptoms of depression described in The International Classification of Diseases (ICD)-10 Classification of Mental and Behavioural Disorders: Diagnostic Criteria for Research, and none of the questions is culture-specific. As the official language of the Solomon Islands is English, PSQ4D could be used as is in principle. The healthcare workers noted the answers of the participants.

\section{Definition of study parameters}

In this study, we defined obesity as BMI $\geq 30 \mathrm{~kg} / \mathrm{m}^{2}$, malnutrition as BMI $<18.5 \mathrm{~kg} / \mathrm{m}^{2}$, hypertension as systolic blood pressure $\geq 140 \mathrm{~mm} \mathrm{Hg}$ or diastolic blood pressure $\geq 90 \mathrm{~mm}$ $\mathrm{Hg}$, diabetes as HbAlc level $\geq 6.5 \%$, inflammation as CRP level $\geq 1 \mathrm{mg} / \mathrm{dL}$ and depressive mental state as $\geq 3$ items positive for the PSQ4D survey.

\section{Interview survey}

All participants were interviewed individually to gather information on their gender and date of birth as well as their livelihood and lifestyle (see online supplemental material 1). These interviews were conducted to determine the socioeconomic status of the participants and/or control for confounding factors. This interview survey included the Humanitarian Emergency Settings Perceived Needs Scale (HESPER) to validly assess the perceived needs of people in each community. The HESPER assessed the physical, mental and social needs of the people. ${ }^{19}$ Because HESPER has too many items as variables and because it is a questionnaire that represents the community as a whole rather than individuals, we used it to examine differences in communities and not to analyse individuals' health status.

\section{Statistical analyses}

Tukey's test was used for multiple comparisons of health measures among the three villages. $\chi^{2}$ test was used to compare the prevalence of indicators among the three villages, and Fisher's exact test was adopted for instances of small sample size. In the Solomon Islands and other societies in Oceania, the degree of modernisation is known to be related to health status, and a modernity score has been used to determine how many modern objects an individual has. ${ }^{20}{ }^{21}$ In this study, we examined the ownership of various modern objects but decided to use overall modernity as a variable rather than analysing individual ownership, because people who lead modern lives tend to own more than one thing. Owning several modern goods was summarised into one factor by principal component analysis; the strongest first principal component was used as the variable. This factor explained $38.9 \%$ of the total variation. Further, logistic regression analysis was conducted to explore risk factors for communicable diseases, NCDs and mental diseases, and the effects of community differences were analysed after adjusting for age, sex, housing style (as an indicator of living environment), and owning modern goods (socioeconomic status). The variable of housing style was added as an indicator of socioeconomic status because Western-style houses are durable and can be lived in for more than 10 years, while traditional houses are usually changed every few years; thus, living in a Western-style house is considered a status symbol in rural areas. ${ }^{9} 20$ Missing data, if any, were excluded from each analysis. All statistical analyses were conducted using the R V.4.0.5 (The R Project for Statistical Computing), and a $\mathrm{p}<0.05$ was considered statistically significant.

\section{RESULTS}

Table 2 shows the household-level living environment and socioeconomic status of the participants. Regarding garden crops, fish and cash income, more than $80 \%$ of the participants from Sasamungga and Taro answered that they had sufficient amounts of these. However, in Manuopo, about half the participants had enough crops or fish, and only $29.0 \%$ had enough cash income. The proportion of Westernstyle houses was the highest in Taro $(68.8 \%)$, followed by Sasamungga (63.3\%), with the lowest in Manuopo (10.1\%). 'Owning modern goods' was the most common in Taro and least common in Manuopo.

Table 3 shows the health status of the participants. Body weight and BMI were the highest in Taro and the lowest in Manuopo, indicating that the prevalence of being overweight or obese was higher in Taro compared with Manuopo. Hypertension was more prevalent in Sasamungga than the other two villages, while more inhabitants of Manuopo had depressive conditions than in other villages. No cases of malaria and significant differences in communicable diseases (ie, inflammation measured by CRP levels) and malnutrition were observed among the three communities.

Results of the logistic regression analyses for health indicators are shown in table 4. Compared with Sasamungga, living in Taro was a significant risk factor for obesity; females also showed a higher risk for obesity across the three villages. After controlling for the effects of age, the inhabitants of Manuopo 
Table 2 Living environment and socioeconomic status of participating households (\% in parentheses; $n=312$ )



DVD, digital video disc; $\mathrm{HH}$, household; OBM, outboard motor.

showed a decreased risk of hypertension. Participants living in Manuopo had the highest risk of depressive conditions.

Table 5 shows the participants' perceived needs; details are available in online supplemental material 2. Of the three communities, Manuopo inhabitants were more likely to perceive serious problems in all items except for lack of 'respect'. Of the 26 items, the majority of the Manuopo participants answered 'yes' to 11 or more items. Compared with Sasamungga and Taro, more than double the Manuopo participants perceived serious problems with 'food' (37.4\%), 'place to live in' (16.5\%), 'income or livelihood' (77.5\%), 'support from others' (50.0\%), and others. Alcohol and drug use was recognised as a very common problem in all three communities. In addition, issues with law and justice, violence on women and toilets were recognised as severe problems by $40 \%$ or more of the participants in all three communities.

\section{DISCUSSION}

This study was conducted in two communities that are affected by rising sea levels and one comparison community. It revealed that inhabitants of the urbanised island

Table 3 Adult health status of participants measured by biological markers $(n=384)$

\begin{tabular}{|c|c|c|c|c|}
\hline & $\begin{array}{l}\text { Sasamungga } \\
(\mathrm{N}=113)\end{array}$ & $\begin{array}{l}\text { Taro } \\
(\mathrm{N}=116)\end{array}$ & $\begin{array}{l}\text { Manuopo } \\
(\mathrm{N}=155)\end{array}$ & Village comparison* \\
\hline Height (male), cm & $164.9 \pm 0.8$ & $167.3 \pm 0.8$ & $165.2 \pm 0.9$ & NS \\
\hline Weight (male), kg & $68.4 \pm 1.5$ & $77.9 \pm 2.2$ & $65.1 \pm 1.6$ & $\mathrm{~T}>\mathrm{S}, \mathrm{M}$ \\
\hline Weight (female), kg & $67.9 \pm 1.6$ & $71.2 \pm 1.6$ & $60.6 \pm 1.0$ & $\mathrm{~T}, \mathrm{~S}>\mathrm{M}$ \\
\hline$\%$ Obesity & $25.7 \%$ & $37.1 \%$ & $10.3 \%$ & $\mathrm{~T}, \mathrm{~S}>\mathrm{M}$ \\
\hline$\%$ Malnutrition & $0.9 \%$ & $0.9 \%$ & $3.2 \%$ & NS \\
\hline \% Hypertension & $26.5 \%$ & $12.1 \%$ & $13.5 \%$ & $\mathrm{~S}>\mathrm{T}, \mathrm{M}$ \\
\hline$\%$ Diabetes & $1.8 \%$ & $2.6 \%$ & $0.65 \%$ & NS \\
\hline
\end{tabular}

${ }^{*}$ Tukey's test for multiple comparison $(p<0.05)$.

BMI, body mass index; M, Manuopo; NS, not significant; S, Sasamungga; T, Taro. 





Table 5 Participants' responses (percentage answering 'yes') to the Humanitarian Emergency Settings Perceived Needs Scale

\begin{tabular}{|c|c|c|c|}
\hline $\begin{array}{l}\text { Do you have a serious problem because of the } \\
\text { following items? }\end{array}$ & Sasamungga, $\%$ & Taro, \% & Manuopo, \% \\
\hline 1.Drinking water & 21.2 & 24.1 & 38.1 \\
\hline 2.Food & 10.6 & 7.6 & 37.4 \\
\hline 3.Place to live in & 8.0 & 4.3 & 16.5 \\
\hline 4.Toilets & 43.4 & 42.2 & 78.4 \\
\hline 5.Keeping clean & 11.5 & 6.0 & 28.1 \\
\hline 6.Clothes, shoes, bedding, or blankets & 8.0 & 5.2 & 33.8 \\
\hline 7.Income or livelihood & 19.5 & 23.3 & 77.5 \\
\hline 8.Physical health & 29.2 & 9.5 & 43.5 \\
\hline 9. Healthcare & 3.5 & 14.6 & 51.4 \\
\hline 10.Distress & 38.9 & 37.1 & 57.2 \\
\hline 11.Safety & 17.7 & 11.2 & 47.8 \\
\hline 12.Education for your children & 6.2 & 13.8 & 18.8 \\
\hline 13.Care for family members & 23.0 & 17.2 & 32.6 \\
\hline 14.Support from others & 23.9 & 23.3 & 50.0 \\
\hline 15.Separation from family members & 21.2 & 9.5 & 17.4 \\
\hline 16.Being displaced from home & 6.2 & 0.9 & 10.1 \\
\hline 17.Information & 50.4 & 12.9 & 70 \\
\hline 18. The way aid is provided & 44.2 & 18.1 & 75.4 \\
\hline 19.Respect & 34.5 & 29.3 & 24.6 \\
\hline 20.Moving between places & 3.5 & 4.3 & 10.1 \\
\hline 21. Too much free time & 23.9 & 25.0 & 67.4 \\
\hline 22.Law and justice in your community & 47.8 & 49.1 & 75.4 \\
\hline $\begin{array}{l}\text { 23.Safety or protection from violence for women in your } \\
\text { community }\end{array}$ & 51.3 & 42.2 & 68.1 \\
\hline 24.Alcohol or drug use in your community & 92.0 & 82.8 & 96.4 \\
\hline 25.Mental illness in your community & 32.7 & 38.8 & 38.4 \\
\hline $\begin{array}{l}\text { 26.Care for people in your community who are on their } \\
\text { own }\end{array}$ & 38.1 & 31.9 & 47.1 \\
\hline
\end{tabular}

Values in boldface indicate that more than $50 \%$ responded 'yes' ( $n=384$; see online supplemental material 2 for details).

community faced a high risk of obesity, while those of the remote island community faced a high risk of depressive conditions. Further, inhabitants of the urbanised community had better livelihoods and perceived fewer serious problems in their daily lives than those of the remote community. The communities of Taro and Manuopo were selected from among areas of the Solomon Islands where the rise in sea level is particularly severe. This result is valuable as it indicates the health status of inhabitants of islands exposed to sea-level rise.

These findings should be interpreted with caution due to the limitations of our study. First, a causal relationship between the differences in health status found in this study and sea-level rise cannot be inferred from the results of this study alone. These areas are already experiencing vegetation loss and coastal erosion, and additional research will help clarify the causal relationship when the sea-level rise worsens and adaptive measures such as whole-island resettlement are implemented. In our survey method, participation in the survey was voluntary for the inhabitants, so it is undeniable that there may be some bias among the participants. However, this method is unavoidable in order to respect people's will and right to participate in the survey in a country such as the Solomon Islands where there are no official health statistics. Since the same recruitment method was used in all three communities, the results of the cross-sectional comparison are reasonable.

Careful interpretation of the results of the mental health survey for depression is necessary. The possibility of overestimation cannot be denied, given that even in developed countries, where detailed studies have been conducted, the incidence of depression is approximately $10 \%$, and even among low-income groups, it is less 
than $20 \% .^{22}$ Although no precise studies examined the percentage of the population affected by depression in the Solomon Islands, WHO estimated it to be about $2.9 \%{ }^{23}$ For example, in Indonesia, a tropical island country for which statistical data are available, the WHO put the figure at about $3.7 \%$, but a national survey suggested that $23.5 \%$ of the adult population is depressed ${ }^{24}$ In light of this, the fact that over $30 \%$ of the people in the villages included in this study reported symptoms of depression indicates that scores on a 4-item screening test should not be taken as the prevalence of diagnosed depression in the community.

In addition, our study design did not account for all confounding factors because small island communities potentially face hardships other than the sea-level rise. Hypertension may be influenced by lifestyle factors, and its high prevalence in Sasamungga was not explained in this study. This finding of high prevalence of hypertension in an intermediately urbanised village is similar to the findings reported by other studies. ${ }^{9}$ This high incidence is probably the result of a change from a traditional diet to a Western one, with an increased use of salt. ${ }^{925}$ However, as more urbanised populations may have received medical information to reduce salt intake to avoid hypertension, further studies are necessary.

While this study has limitations, it sheds light on the problems and health risks of small island communities. First, even though the inhabitants of Taro face potentially severe impacts of rising coastal water levels, a relocation plan has already been established for which financial support is being raised. ${ }^{6}$ Nevertheless, Taro inhabitants have access to food, medical services, education and other resources, as it is the provincial capital and resources are brought in. Therefore, Taro participants did not show serious health problems due to lack of resources but rather showed greater risk of developing NCDs, similar to other urbanised communities in the Solomon Islands. ${ }^{89} 26$ This health problem is thought to result from a combination of a diet of purchased foods and low physical activity on the small island.

Second, and in contrast with Taro Island, the findings from Manuopo participants supported those of previous studies that rural people are physically healthier than urban or periurban people in terms of incidence of NCDs. ${ }^{89} 27$ However, third and importantly, this study found that Manuopo inhabitants showed a high risk of depressive conditions (approximately 60\%). Even though there is an assumption that people living in traditional societies are mentally healthy, ${ }^{28}$ a wide range of mental health challenges were observed in communities in the aftermath of conflicts and disasters. ${ }^{29}$ Therefore, the high prevalence of depressive symptoms in Manuopo is thought to reflect the hardships of life in the remote small island. The HESPER results and the interview on the socioeconomic status suggested that the people of Manuopo, which is remote from the main islands, simply experience a lack of livelihood, food, and other materials as well as information. High concerns regarding issues related to alcohol and drug use, law and justice, and violence against women were commonly recognised in Guadalcanal Island of the Solomon Islands, which had been affected severely by ethnic conflicts between 1998 and $2003,{ }^{29}$ and the same pattern was observed in the three communities selected in this study. The high incidence of depressive conditions in Manuopo is thought to arise from a variety of stresses in everyday life and survival fears such as those related to a shortage of food and other basic human needs, including fear for the future. Future studies are expected to examine changes that occurred due to such survival fears in Manuopo and in other Solomon Islands communities that also face a high prevalence of mental health challenges.

The results of this study have important implications for small island communities' adaptation to climate change. Concerns have been raised about the increasing prevalence of mental illness under the threat of sea-level rise and adaptation to it (eg, involuntary migration); however, only a few studies have investigated this factor in the South Pacific. ${ }^{10}$ Interviews with 100 people from Tuvalu suggested that distress could result from either (1) local environmental impacts being caused or exacerbated by climate change or (2) hearing about global climate change and contemplating its future implications. ${ }^{31}$ This study conducted a rare direct measurement of mental health that supported the consideration that people living in small islands and vulnerable to threats related to the security of food and livelihood, climate change and others are at a higher risk of depressive conditions. This study also indicates that depressive conditions are widely observed (over $30 \%$ of the sample) even in places with adequate employment, transportation and communication infrastructure (eg, Taro). Moreover, migration to urban areas is not a solution because previous studies have shown that remote island people migrating to urban areas far from their homeland also face potential risks of mental disorders. ${ }^{27}$ In addition, living in urban areas or evacuation camps is known to be associated with physical illness, as shown in this study's findings for Taro and in a previous study on the health impacts of a disaster. ${ }^{9}$

This observational study, thus, concluded that small island communities displayed different health problems: the risk of increased NCDs is associated with the urbanised community, and that of mental disorders is associated with the remote community. These health problems should be monitored during future socioeconomic and climatic changes. Since the health and well-being of small island populations depend on their social and ecological environments, the implication is that policy-makers should develop climate action plans that are in harmony with the various environmental factors.

\section{Twitter Takuro Furusawa @takurofurusawa}

Acknowledgements We sincerely thank all the participants of this study, the community and church leaders in the communities selected for the study, and the staff of the Ministry of Health and Medical Services in Solomon Islands. Editage contributed through English editing of the manuscript. 
Contributors TF conceived the project. TF, TI, TT and FP designed the study. TF, FP, SG, TI, TT and AS collected the data. TF performed the statistical analyses and wrote the manuscript draft. FP, SG, TI, TT and AS read and made significant changes to the manuscript and produced this paper. TF is the guarantor of this paper.

Funding TF, TT and TI received KAKENHI Grant-in-Aid for Scientific Research (B) (15H05123) and Grant-in-Aid for Scientific Research (A) (20H00045) from the Japan Society for the Promotion of Sciences.

Map disclaimer The depiction of boundaries on this map does not imply the expression of any opinion whatsoever on the part of BMJ (or any member of its group) concerning the legal status of any country, territory, jurisdiction or area or of its authorities. This map is provided without any warranty of any kind, either express or implied.

Competing interests None declared.

Patient consent for publication Not applicable.

Ethics approval This study was approved by the Solomon Islands Health Research and Ethics Review Board (HRE No. 013/16), Ministry of Health and Medical Services, Solomon Islands, as well as the Kyoto University Graduate School and Faculty of Medicine Ethics Committee (G0353), Graduate School of Asian and African Area Studies, Kyoto University.

Provenance and peer review Not commissioned; externally peer reviewed.

Data availability statement Data are available on reasonable request. Data except for personal information are available on reasonable request.

Supplemental material This content has been supplied by the author(s). It has not been vetted by BMJ Publishing Group Limited (BMJ) and may not have been peer-reviewed. Any opinions or recommendations discussed are solely those of the author(s) and are not endorsed by BMJ. BMJ disclaims all liability and responsibility arising from any reliance placed on the content. Where the content includes any translated material, BMJ does not warrant the accuracy and reliability of the translations (including but not limited to local regulations, clinical guidelines, terminology, drug names and drug dosages), and is not responsible for any error and/or omissions arising from translation and adaptation or otherwise.

Open access This is an open access article distributed in accordance with the Creative Commons Attribution Non Commercial (CC BY-NC 4.0) license, which permits others to distribute, remix, adapt, build upon this work non-commercially, and license their derivative works on different terms, provided the original work is properly cited, appropriate credit is given, any changes made indicated, and the use is non-commercial. See: http://creativecommons.org/licenses/by-nc/4.0/.

ORCID iD

Takuro Furusawa http://orcid.org/0000-0001-7772-3053

\section{REFERENCES}

1 Herlihy N, Bar-Hen A, Verner G, et al. Climate change and human health: what are the research trends? a scoping review protocol. BMJ Open 2016;6:e012022.

2 Haines A, Kovats RS, Campbell-Lendrum D, et al. Climate change and human health: impacts, vulnerability and public health. Public Health 2006;120:585-96.

3 Intergovernmental Panel on Climate Change. Part A: global and sectoral aspects. working group II contribution to the fifth assessment report of the Intergovernmental Panel on Climate Change. In: Climate change : impacts, adaptation, and vulnerability. Cambridge, UK, and New York: Cambridge University Press, 2014.

4 World Health Organization. Climate change and human health: impact and adaptation. Geneva: World Health Organization, 2000.

5 Woodward A, Smith KR, Campbell-Lendrum D, et al. Climate change and health: on the latest IPCC report. Lancet 2014;383:1185-9.

6 Fritze JG, Blashki GA, Burke S, et al. Hope, despair and transformation: climate change and the promotion of mental health and wellbeing. Int J Ment Health Syst 2008;2:13.

7 Ohtsuka R, Ulijaszek SJ. Health change in the Asia-Pacific region. Cambridge: Cambridge University Press, 2007.

8 NCD Risk Factor Collaboration (NCD-RisC). Rising rural body-mass index is the main driver of the global obesity epidemic in adults. Nature 2019;569:260-4.

9 Furusawa T, Furusawa $\mathrm{H}$, Eddie $\mathrm{R}$, et al. Communicable and noncommunicable diseases in the Solomon Islands villages during recovery from a massive earthquake in April 2007. N Z Med J 2011;124:17-28.

10 Mclver L, Kim R, Woodward A, et al. Health impacts of climate change in Pacific island countries: a regional assessment of vulnerabilities and adaptation priorities. Environ Health Perspect 2016;124:1707-14.

11 Haines P, McGuire S, Rolley K. Integrated climate change risk and adaptation assessment to inform settlement planning in Choiseul Bay, Solomon Islands. Brisbane: BMT WBM Pty Ltd, 2014.

12 Albert S, Leon JX, Grinham AR, et al. Interactions between sea-level rise and wave exposure on reef island dynamics in the Solomon Islands. Environ Res Lett 2016;11:054011.

13 Solomon Islands Government. Population \& Housing Census: Report on Migration and Urbanisation. 2011. Honiara: Solomon Islands: National Statistics Office, 2009.

14 Solomon Islands Government. Provincial profile of the 2009 population and housing census: Choiseul. Honiara: Solomon Islands National Statistics Office, 2011.

15 Albert S, Grinham A, Gibbes B. Solomon Islands: rising sea levels blamed for the disappearance of five reef islands, 2016. Available: https://www.abc.net.au/news/2016-05-07/rising-sea-levels-blamedfor-wiping-out-five-islands/7392986 [Accessed 17 Jun 2021].

16 McNaught R, CVudi N, Tego G. The adaptive capacity of pileni island community, Viakau ward, Temotu Province, Solomon Islands. Solomon Islands: Australian Government Department of Climate Change and Energy Efficiency, 2011. https://www.environment.gov. au/system/files/resources/827a49d2-5fa6-45d1-866f-dc9f11ec116b/ files/sirc-report.pdf

17 Solomon Islands Government. Provincial profile of the 2009 population and housing census: Temotu. Honiara: Solomon Islands National Statistics Office, 2011.

18 Indu PS, Anilkumar TV, Pisharody R, et al. Primary care screening questionnaire for depression: reliability and validity of a new four-item tool. BJPsych Open 2017;3:91-5.

19 Semrau M, van Ommeren M, Blagescu M, et al. The development and psychometric properties of the humanitarian emergency settings perceived needs (HESPER) scale. Am J Public Health 2012;102:e55-63.

20 Furusawa T. Living with biodiversity in an island ecosystem: cultural adaptation in the Solomon Islands. Singapore: Springer, 2016.

21 King H, Finch C, Collins A, et al. Glucose tolerance in papua New Guinea: ethnic differences, association with environmental and behavioural factors and the possible emergence of glucose intolerance in a highland community. Med J Aust 1989;151:204-10.

22 Brody DJ, Pratt LA, Hughes JP. Prevalence of depression among adults aged 20 and over: United States, 2013-2016. NCHS Data Brief 2018:1-8.

23 World Health Organization. The global health observatory: estimated population-based prevalence of depression, 2021. Available: https:// www.who.int/data/gho/data/indicators/indicator-details/GHO/ estimated-population-based-prevalence-of-depression [Accessed 25 Aug 2021].

24 Astutik E, Hidajah AC, Tama TD, et al. Prevalence and determinants of depressive symptoms among adults in Indonesia: a cross-sectional population-based national survey. Nurs Forum 2021;56:37-44.

25 Furusawa T, Naka I, Yamauchi T, et al. Hypertension-susceptibility gene prevalence in the Pacific islands and associations with hypertension in Melanesia. J Hum Genet 2013;58:142-9.

26 Furusawa T, Naka I, Yamauchi T, et al. The serum leptin level and body mass index in melanesian and micronesian Solomon Islanders: focus on genetic factors and urbanization. Am J Hum Biol 2011;23:435-44.

27 Nakazawa M, Yamauchi T, Tanaka M. Community health assessment by urine dipstick screening in relation to the variety of lifestyles in the Solomon Islands. Peop Cult Oceania 2002;18:35-44 https://ci.nii.ac. jp/naid/110003474504

28 Hidaka BH. Depression as a disease of modernity: explanations for increasing prevalence. J Affect Disord 2012;140:205-14.

29 Blignault I, Bunde-Birouste A, Ritchie J, et al. Community perceptions of mental health needs: a qualitative study in the Solomon Islands. Int J Ment Health Syst 2009;3:6.

30 Tiatia-Seath J, Underhill-Sem Y, Woodward A. The nexus between climate change, mental health and wellbeing and Pacific peoples. Pac Health Dialog 2018;21:47-9.

31 Gibson KE, Barnett J, Haslam N, et al. The mental health impacts of climate change: findings from a Pacific island Atoll nation. J Anxiety Disord 2020;73:102237. 